\title{
Kurdish Students' Motivation to Study in Hungary
}

\author{
Sana Khudur \\ PhD Candidate in Eotvos Lorand University (ELTE) in Budapest, Hungary \\ san_soul@yahoo.co.uk
}

\begin{abstract}
Abstarct : The present study intends to explore the motivation of Kurdish students to study in Hungary. To answer the query of the study; an in-depth qualitative interview method was employed. Nine higher education level students (BA, MA or PhD), five males and four females who are studying at four different universities in Hungary were interviewed. Individual face to face interviews were organised to engage into the details of what could be achieved from the participants and to discover their study experiences deeply. Based on the collected data outcomes; a process model of Kurdish student motivation to study in Hungary was designed which identifies the main stages of their motivational behavior in a process way from the initial wishes to accomplishments. The findings reveal that several reasons have impacts on responders`decision making and the choice of country. Also, the participants are highly motivated on their studies because of the future accomplishments they could gain as the result of pursuing their studies abroad and getting an international qualification.
\end{abstract}

Keywords : Overseas education; choice motivation; executive; motivation; achievement motivation; adjustment

\section{Introduction}

Motivation of students`seeking international education has become the critical issue in the world today and the heated topic of discussions by many researchers and academics. With the advancement of economy, business and culture towards globalisation; education has expanded towards international trends as well (Wang \& Shan, 2006; Edward \& Ran,2006). And this, resulted in increasing the diversity of student body in the international educational context. Worldwide educational organisations and universities are competing thoroughly against each other in order to achieve their goals and host larger number of students each year.

Considerable number of studies (Naceur, 2009; Baldwin \& James,2000) for example, indicated the development of economy and the prosperity of a country based on the demands of international students seeking higher education in that country. However, it is important to understand the determinant aspects that attract students`attention, influence their decision making and lead them to choose that country as the study destination. Besides, what effects this study will create to the students` future life and careers as a result of obtaining an international degree.

A considerable number of studies indicated the philosophy of international students study experiences (see Mazzarol\&etal., 2002; Payne,2001; Wang\& Shan, 2006; Zeeshan\& etal., 2013; Safakli \& Ihemeji,2015). Nonetheless; no attempts have been approached so far to investigate the case of Kurdish students motivation to study in a foreign country; and Hungary in particular. Therefore; this motivated the researcher to design a study and provide some realistic data to explore and find the answer to the query: What motivates Kurdish students` to study in a foreign context like Hungary? 


\section{Review of Literature}

Previous literaturehas provided noteworthy studies in relevance to student motivation studying abroad and the country choice. This researchreviews some of the studies that were recentlyimplemented in the mentioned area and sheds the light on theprocessof student motivation while studying overseas along with the difficultiesthat may face during pursuing their studies.

To begin with, there isprofound number ofdefinitionswith regard to motivation in second or foreign language learningwere presented by scholars. This study interested in the one that is presented by Dörnyei \& Ushioda, where motivation described as "what moves a person to make certain choices, to engage in action, to expend effort and persist in action" (2011: 3). Therefore; in this respect, motivation is the choice, persistence and effort to achieve a goal.

Also, various pointsconcerning studentmotivation to study abroad have been pointed out through researches and they were mainly distinguishedas push and pull reasons (see Mazzarol\&etal., 2002; Bamford\&etal., 2002).This study has analyzed some of these researches and demonstrated the main finding in the following discussions.

In a study conducted byBaldwin and James(2000) motivation of students migrating to other countries hasinvestigated and suggested that students` decision making is empowered by a combination of a number push and pull aspects.Economic and political factors appeared to be the most significant push factors despite the difficulties of gettingthe desired coursers in home country and also limited variety of course subjects. Institutional factors, on the other hand, such as teaching quality, better perception of course varieties, international reputation of the institution, location, degree of innovation and the use of technology found to be the most important factors that tend to pull students to make the choice of overseas studies.

In another study, Zeeshan \&etal. (2013) further investigated that according to many researchers who researched students' motivation to study abroad; a number of reasons affect students to decide and choose another country as their study destinations. The reasons are more explicitly indicate:

1. Experiencing another life, culture and country and discovering more about them.

2. Studying in an international universitythat has a good educational reputation.

3. Improving language knowledge.

The authors came to the conclusion that the students' new academic and cultural experiences can impact their own schools and society when they return back their home countries after obtaining their degrees.

Notableresearchers studied the push and pull aspects that were discussed above in their researches and agreed that the aspects would affect the students 'decision making and choice of the country of study in profound ways (Mazzarol\&etal., 2002)

Davey (2005) observes that decision making isa multistage processthat is undertaken consciously or subconsciously by a student planning to enter higher education studies and ends by choice of a program and country as the study destination.He further elaborates that both concepts are interrelated and cannot be separated from each otherand both are influenced by a range of conditions; namely, contextual, organizational, personal and the internal aspects that manifest the individuals`value and perceptions.

It has also discovered that there are motivational divergences on students` decisions of studying abroad. For example, the most important reason for European students to choose to study abroad is to have a better opportunity to be proficient users of English language and to 
get familiar with cultural traditions. Unlikely; Taiwanese studentsconsider other reasons, namely the international recognition of their qualification and the opportunity to get a good job,as the most important aspects for studying overseas. And these motivational differences, by no means, have essential implications for international students` marketing and recruitment strategies (Edwards \& Ran, 2006)

Studies on international students' study experiences alsopoint out that the overseas students have to adjust themselves in the foreign contextwith several aspects. These aspects include social, cultural, psychological and academic; despite the fact that international students may encounter many other challenges while they are experiencing a new life. Nonetheless, as Li and Ching (2000) maintain, most of the researchers concluded that overseas students generally make reasonable adaptations of their new life to a very good extent. Wang and Shan(2006)further details that based on what have discovered from the previous studies; it would be inappropriate to consider academic issues separately from other social and cultural challenges. As he perceives, international students' cultural adaptation is the most effective way to explore about their study experiences overseas and he insists that successful learning is achieved by developing cultural comprehensionin order to overcome the unbalancesthat may occur and mediate higher order of thinking and construction of knowledge.

With regards to cultural adjustment as the determinant factor of foreign language learning success; Schmidt and etal. (1996) performed a quantitative study in an attempt to identify the components of foreign language learning motivation of an adult learner with regard to specific classroom, practice, activity preference and learning strategies that boost learners `oreign language learning motivation. This research is relevant to what I tend to find out in two basic ways. Firstly, it identifies the factor of sociability as the part of foreign language learning motivation in addition to attributes based on the components of motivation and group cohesion that emerges in foreign language learning context. Secondly, the study has provided profound evidences of the importance of attributions of success and failure in foreign language learning motivation. This research appeared to be different with regard to learners` self expectationsof success and failure because statements concerning external issues that may cause failure or internal ones that may cause success analyzed as independent factors. Comparing to other studies that explored these factors, this study could be placed as the primary study that found an obvious relationship between items that dealing with expectations for success in connection to internal factors, ability and effort as determinations to success. Therefore, it was found that learners ' with high expectations of success towards a specific task, enrolling in a language course for example, would be more involved in the task and persist longer to face the difficulties in order tosustain the goals than learners with low expectations of success who may be less persistent and may give up easily.

It can be argued that the current study is primarily motivated by Dörnyei andOtto's(1998) process model of student motivation. The model was introduced to change the focus of traditional concerns of motivational study from the preactional stage "choice motivation" to the action stage that is "goal achievement". The authors have designed the study in order to serve as the theoretical basis for the methodological functions as they believed that the existing models lack of having adequate information in ways that they disregard the role of motivational source of executive behavior and they do not provide detailed relevance on motivational influence on action behavior. They also wanted to determine the fact that motivation is not static, but dynamic and changing in time, therefore it is necessary to contain some features of temporal axis. 
The writers come to the conclusion that it is difficult to be able to explain a large proportion of variances in motivated learning behavior by focusing only on a few selected factors that discussed in the model.

\section{Methodology}

The study was inspired by the researcher`s personal study experience in Hungary. I sought the opinions of Kurdish students who are currently experiencing their higher education studies (BA, MA or PhD) and enrolling at four universities in Hungary.

An in-depth qualitative interview method was employed in this study in an attempt to get engaged with the details of what is being conveyed by the participants. For this, a number of comprehensive questions were included in the instrument to stimulate learners to talk freely concerning various aspects of their studies and gave them opportunity to highlight almost all the positive and negative corners of their study experiences. The sample of the study comprised nine students, five males and four females, who study in various range of majors, including (Hydrogeological Engineering, Chemical Engineering, Archeology Geosciences and Political Sciences).

Pilot interview was conducted first to see the effect of the instrument; then minor modifications were made to maintain that the interview questions were clear and understood by the interviewees. Following this, all the interviews were conducted face to face and online in responders ' mother tongue, Kurdish, to capture expressive and developed responses and were recorded upon the participants` consent, each took around 20-30 minutes. Since the researcher was part of the main focus of the study and keen on various concerns the students might have experienced; perceived issues could have been discussed very realistically and not surprisingly; further points were raised and conveyed by the participants.

After conducting all the interviews; the data was transcribed, codes were given from 1-9 and then each interview was translated from Kurdish to English.

As the final step, all the emerging themes were underlined and the students motivational behavior was studied in a process way according to three phases. Based on the most focused emerging themes from the data; a model of Kurdish students 'motivation to study in Hungary was designed.

\section{Findings and Discussion}

This is an explanatory study that expands what is already known about overseas students. The study was originally affected by Dörnyei and Otto`s(1998) process-oriented approach to second language motivation as it has already discussed in the review of literature. The researcher intended to find out Kurdish students` motivational behavior process while they seek their higher education studies in a foreign context like Hungary. The study wanted to investigate what affects the students decision making, the choice of the country and how motivated are they to persist while they face challenges to accomplish their goals. Sufficient data collected and assisted to design the model below in order to study students motivation as a process from the pre-actional phase, that is the decision making, to actional and post actional phases which indicate the outcome of their studies in Hungary. Besides, theparticipants` expectations towards the opportunities that their studies will bring to their life were included. The findings are detailed and analyzed based on the ordered phases. 


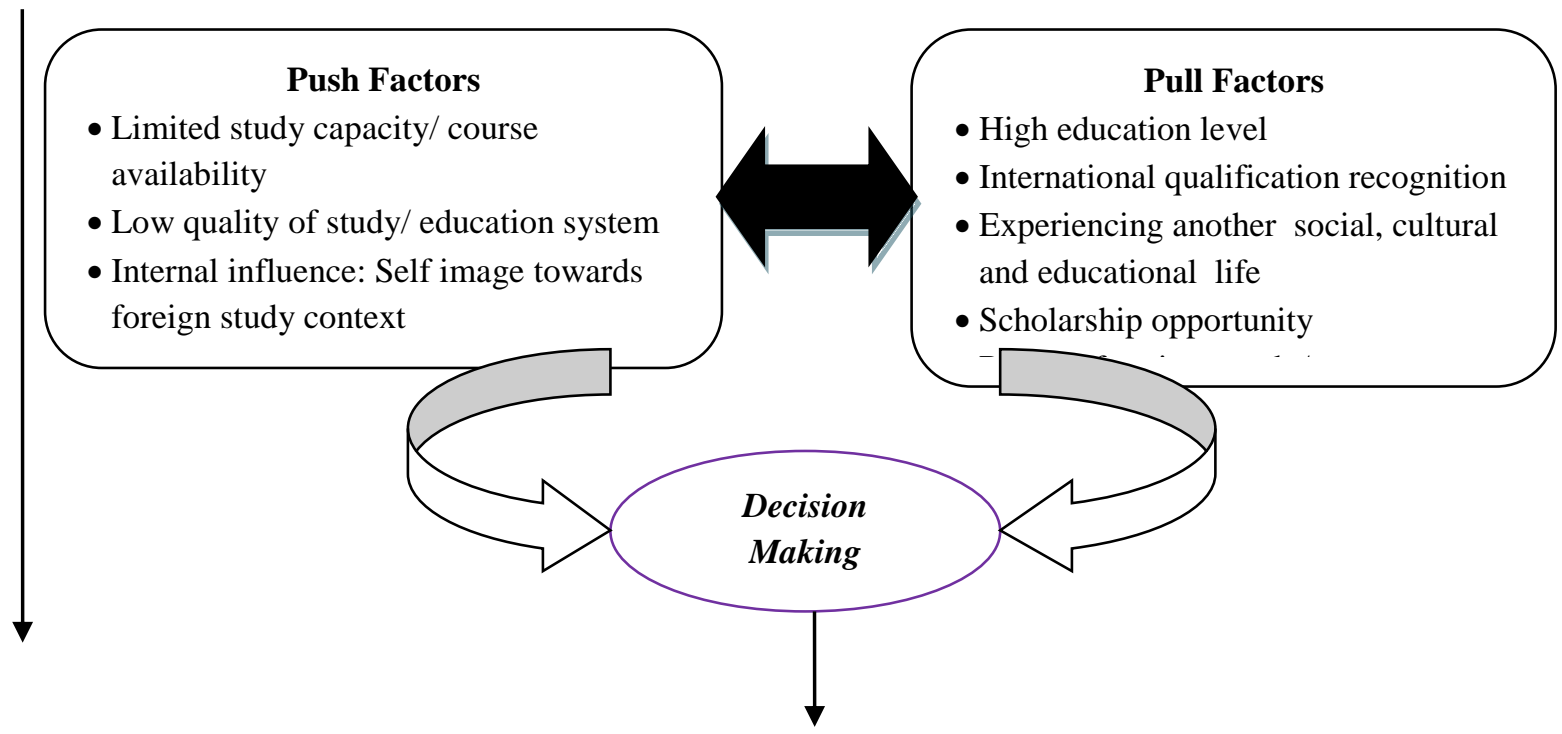

Actional Phase

\section{Executive Motivation}
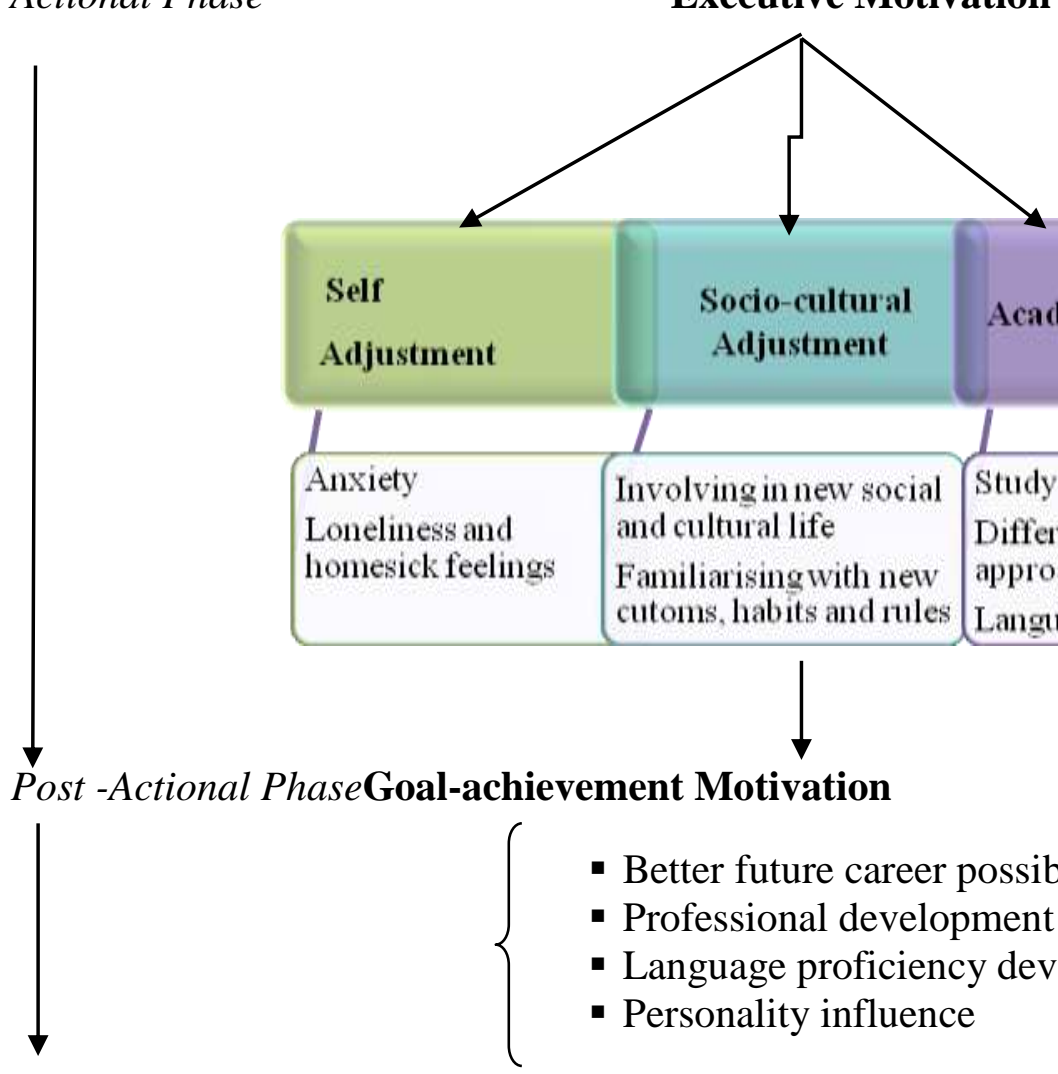

Self

Socio-cultural

Academic Adjustment

Adjustment

\begin{tabular}{ll|l|}
$\begin{array}{l}\text { Loneliness and } \\
\text { homesick feelings }\end{array}$ & $\begin{array}{l}\text { Involving in new social } \\
\text { and cultural life } \\
\text { Familiarisingwith new } \\
\text { cutoms, habits and rules }\end{array}$ & $\begin{array}{l}\text { Study system shock } \\
\text { Different learning and teaching } \\
\text { approaches }\end{array}$ \\
\hline Language proficiency issues
\end{tabular}

Figure 1. The Process Model of Kurdish Students`Motivation to Study in Hungary 


\subsection{Choice Motivation}

This indicates the pre-actional phase where various issues stimulate students and arouse their interests to come to the decision to pursue their studies abroad. They were distinguished as push and pull reasons.

a) Push reasons : referred to those country aspects that operate to push students to make the decision to seek international studies. They are extremely important as they provide a basis for broad conceptualization of the established context of the countries of origin.Several points appeared as the push reasons based on the data collected which motivate Kurdish students to decide to study in Hungary, among them, limited study capacity or course availability; low quality of education; political and economic influences.

Family impact, on the other hand, is another significant factor that seemed to have a profound impact on the participants` choice motivation. Most of the interviewees stated that parents interest of having a high international qualification played a vital role on motivating them and lead them to come to the decision to study abroad in order to meet their parents expectations. This can be supported by one of the participants` quotes, who states:

My family (by no doubt) had the most influential impact on my choice to study in Hungary. And now, as I am in the middle of the way, they still have influence on me in order to achieve my goal. My aim is to meet my parent's expectations, make their dreams come true and be proud of my accomplishments.

Above all of the push reasons that have already discussed; students` self image towards a foreign study context is another point that almost all of the respondents raised during the interviews and it has clearly seemed to have motivated them at most. The responses indicate that the students wanted to develop themselves personally and professionally, get familiar with a new life style and travel around the world. One of the participants cites:

I wanted to develop myself, depend on myself and meet other people. I wanted to discover different way of living, experience new culture and new life and learn how to face challenges by my own.

b) Pull reasons: These are the reasons that operate the host country appealing to interest students and serve to encourage them to seek study there. Institutional aspects place the top of such reasons, including: high quality of study, international recognition of qualification, availability of a range of various courses and study opportunities and the innovation degree and the use of technology in most of the universities that serves Hungary as interesting for Kurdish students.

Another essential point that needs to be considered and found as vital pull reason for the responders of this study is the opportunity of number of scholarship or sponsorship programs that are provided by either Hungarian government or the private sectors. Collected data from all the interviewees evidence that if such an opportunity were not provided; they could not try their luck to choose Hungary as their study destinations. This is an extract from one of the interviewees` records:

The opportunity of scholarship program cleared me the way to do my MA here. I didn't have a chance to seek my study back home due to the high competitions among applicants and the limited application opportunities. 


\subsection{Executive Motivation}

This is the actional phase of the motivation process in this study which indicates the current state of the participants where they are involved in the actional phase and doing their studies in Hungary. In this stage, three reasons found to have influences on students motivation. The first one is self-adjustment, where the participants raised a number of points that need to be adjusted in order to enable them to cope with the personal difficulties that face them during their stay in Hungary. These issues indicate the feelings of anxiety, loneliness and nostalgia. Nearly all the participants responded that they have experienced such feelings at the very beginning points of their arrivals to Hungary; nevertheless, the extent was varied from one respondent to another. BA students, for example, detailed this issue more seriously than MA or PhD students; as this was the first experience of being abroad for most of them. Two of the BA participants asserted that they regretted the decision of studying abroad and they have passed hard times to get reached to their current points.

One of the BA participant states:

When I first arrived, I was very shocked. Everything was different and new. A number of my colleagues gave up and fled back home but I did my best to persist and continue, because I thought if I decide to give up and go back people may blame me and this failure may destroy the rest of my life.

Along with the self adjustment, socio-cultural and academic life needs to be adjusted in order to help students persist on their studies and achieve their goals. From the data, it becomes clear that social and cultural life would affect students` both academic and personal adjustments as well since the social life serves as a ring that combines all the other sides of student life together. From the review of literature, it has also claimed that social aspect serves as the emphatic part of foreign language learning achievement ( $\mathrm{Li}$ and Ching,2000) since it will constitute the components of motivation and group cohesion Wang and Shan(2006) that are central points in foreign language learning success.

Surprising findings obtained with regard to the participants' social and cultural experiences in Hungary. The participants feelings were very positive and fulfilled social and cultural adjustments perceived from the responders. Nearly all of the participants indicated that they enjoy Hungary`s social and cultural life and they described Hungarians as helpful, tolerant and indicated no apparent discriminations based on race, religion or belief.

As to the academic life adjustments, again contrastive viewpoints were attained among BA, MA and PhD participants as it has observed with self adjustment.

The participants were generally addressed that the study system and learning and teaching methods are very dissimilar to what they have already experienced back home; however, this unlikeness verified differently by the respondents. For example, for BA students, the major difficulty was the language of the study. One of the participants declares:

The major issue that I have faced in my studies is studying in English. Before coming here, we didn't have any recognized English language test, apart from those students who had the test, but their levels were really low. Although we have attended one year basic [pre-engineering for example] course along with academic English course, it didn 't reach us to the required level that enable us to study our majors in English.

Another participant highlighted: 
I am still a bit unsatisfied with my English language level and sometimes I cannot follow the class very well. Whereas I don't let the information pass and try other ways, for example, asking my colleagues to clarify and explain for me after the class time or search in the internet for it.

Among MA students, nonetheless; no obvious study issues were predicted, and students felt that they were on track with their courses. Moreover; some of the students could obtain high degreescompared to their colleagues. This extract from the data proves this point:

My previous knowledge concerning my field [Hydro geological engineering] and my

English language level supported me to progress without any difficulties. I had a good rank among my colleagues in the last year's academic study.

Unlikely, the situation for PhD students seems to be completely different as compared to BA or MA students with regard to academic life experiences. All the three PhD students who participated in this study manifest that their studies are rather less scheduled and less formal. Their class times are not regular and the lion's share of their studies depend on themselves. Their meetings with the lecturers and colleagues are only occasional. It was indicated that though there were courses to attend for each semester, but they were restricted to two or three occasions per semester. This lead them to spend most of their times outside Hungary and practice self study. Therefore, little could have been achieved with regard to their study experiences in Hungary.

\subsection{Goal-achievement Motivation}

It can be considered that students` choice motivation or decision to study in a foreign context is strongly inspired by the opportunities and goal-directed expectations that this decision will bring to their life.

Here, the findings highlighted that all of the responders of this study were motivated by the future attainments as the result of pursuing their studies abroad and getting an international qualification. These attainments include getting a better future career, professional development and language proficiency progress. Results also indicate that the participants believed living in a foreign context and experiencing another social and cultural life will result in producing a stronger personality as far as they get more experienced and could have a more comprehensive understanding towards the life issues.

The results of this study are remarkably in line to what is already discovered by Ushioda (1996) who found that language related enjoyment, learners` own goals and prior language learning experiences are the sources of students` motivation to study abroad. Also, the ways it combines push and pull reasons as the key factors to boost students`attention to demand overseas studies and to affect their decision making which is also claimed by Mazzarol and etal (2002). Once more the outcomes are in parallel with Wang and Shan (2006) who believe that learning shock is due to different knowledge background and learning experiences that the students have experienced in their previous studying.

What can be concluded from the findings of the study is that a number of reasons aremotivating Kurdish students to study in Hungary. These reasons could be summarized as, language proficiency, experiencing another culture and life and also better study opportunities. Finally, these reasons are giving students the energy to imposethe challenges and benefit from countless different experiences which may influence the rest of their life. 


\section{Conclusion}

This study investigated the influencing reasons that motivate Kurdish students to pursue their higher education studies in Hungary. Based on the results; the reasons could be summarized as student's personal attitude towards international education and overseas study context, better study opportunities, parental impacts and the future attainments that are associated with their studies; these mayinclude, better career possibility, higher job positions language proficiency and personal development. Besides, studying abroad benefits one to get familiarize and experience various conditionswhich help to be a self dependent character and be able to comprehend things more overtly.

The author believes that the designed model which studied the impact of students motivation on their behaviors in a process way offers considerable potential practical gains. It helps to understand the main stages of action, initiation and performance. It also manifests how various motivational behavior mechanisms need to be applied in order to maintain, develop, and persist on an ongoing action. The model also offers a practical structure where various forms of adjustments, including (internal, socio-cultural and academic) could be argued as the most affective interrelated issues that can assist students to challenge the difficulties they may face during their studies.

Although the study was restricted to a limited number of participants; it can be still considered as significant in ways it could provide novel insights with regard to Kurdish students` study experiences in a foreign context. However, more significant results can be obtained if the study is applied to a larger scale sample.

\section{References}

Baldwin, G. and James, R. (2000)The market in Australian high education and the concept of student as informed consumer Journal of Higher Education Policy and Management(22)2, 139-148.

Bamford, J., Marr, T., Pheiffer, G. \& Weber-Newth, I. (2002) Some features of the cultural and educational experience and expectation of the international postgraduate students in the UK. Proceedings of the BEST Conference Edinburgh: Scotland

Davey, G. (2005) Chinese students` motivation for studying abroad International Journal of Private Education 2, 16-21

Dörnyei, Z. \& Ottó, I.(1998)Motivation in action: A process model of L2 motivation. Working Papers in Applied Linguistics 4,43-69

Dörnyei, Z. \& Ushioda, E. (2011) Teaching and researching motivation. London: Longman

Edward, V. \& Ran, A. (2006) Meeting the needs of Chinese students in British higher education. Retrieved, Oct. 13, 2016, from:https://blogs.shu.ac.uk/internationalnetwork/files/2013/07/MeetingTheNeeds.pdf

Li, J. T. \& Ching, Y. (2000) Crossing the Border of Education in Wang, T. and Shan., X. (2006) A qualitative study on Chinese postgraduate students' learning experiences in Australia. Accessed, Nov. 8, 2016 from:http://www.aare.edu.au/data/publications/2006/wan06121.pdf 
Mazzarol, T. and Soutar, G. (2002) The Push-Pull Factors Influencing International Student Selection of Education Destination International Journal of Educational Management16(2), 82-90

Naceur, J. (2009) Economic and cultural factors affecting university excellence quality Assurance in Education 17(4), 416-429

Payne, J. (2001) Patterns of participation in full time education after 16: An analysis of the UK youth cohort study DFES: London

Safakli, O. and Ihemeji, O. (2015) Motivation of Students Studying Abroad: Case of Foreign Students in European University of Lefke (Eul) International Journal of Academic Research in Progressive Education and Development 4(4),2226-6348

Schmidt, R., Boraie, D. and Kassabgy, O. (1996) Foreign Language Motivation: Internal Structure and External Connections. In Rebecca, O. (ed) Language Learning Motivation: Pathways to the New Century Honolulu: University of Hawai'i, Second Language Teaching and Curriculum Center

Ushioda, E.(1996) Developing a dynamic concept of motivation. T. Hickley and J. Williams (eds.) Language, education and society in a changing world (pp. 239-245) Clevedon: Multilingual Matters

Wang, T. and Shan., X. (2006) A qualitative study on Chinese postgraduate students' learning experiences in Australia. Retrieved Nov 11., 2016, from:http://www.aare.edu.au/data/publications/2006/wan06121.pdf

Zeeshan, M., Sabbar, D., Sabbar, S. and Hussain, R. (2013). Foreign Students' Motivation For Studying in Malaysia International Journal of Asian Social Science 3 (3), 833-84. 